\title{
ANALISIS FAKTOR YANG MEMPENGARUHI PEMBENTUKAN SERUMEN OBSTURAN
}

\author{
Festy Ladyani Mustofa ${ }^{1}$, Tria Yune ${ }^{2}$, Muslim Kasim ${ }^{3}$ Ega Eryzkia ${ }^{*}$ \\ ${ }^{1,2,3}$ Staf Pengajar Fakultas Kedokteran Universitas Malahayati \\ ${ }^{4}$ Mahasiswa Fakultas Kedokteran Universitas Malahayati \\ Email Koresponden: 16310087@malahayati.ac.id
}

\section{ABSTRACT: ANALYSIS OF FACTORS AFFECTING THE FORMATION OF CERUMENT OBTURANS}

Background : Factors that influence the high incidence of obsturan serumen are widely known theoretically, but have not been studied much. This study aims to find out and prove the factors that influence the formation of obsturan serumen.

Objective: To find out what factors are the risk factors for obsturan serumen in outpatients in Polyclinic ent hospital. Pertamina Bintang Amin Bandar Lampung Methods: Analytical observational research with cross-sectional design. Samples in the form of all outpatients who visited polyclinic ENT HOSPITAL. Pertamina Bintang Amin Bandar Lampung, Dated 1 January - 1 December 2019 which meets the criteria for inclusion and excl.

Results: Patients with obsturan serumen as many as 300 patients and who do not have obsturan serumen as many as 90 patients. The sexes were the most common in women with 156 respondents (51.5\%) and obsturan serumen often occur in patients aged > 18 years as many as 196 respondents (59.5\%) in obsturan serumen education most occurred in low-educated patients, namely as many as 191 (61.8\%) in obsturan serumen work was most common in patients working outdoors as many as 269 respondents (69\%) and in ear cleaning behaviors most common in patients who frequently clean the ears as many as 180 respondents (69\%) and in the history of earaches most found obsturan serumen in those who have a history of earaches as many as 188 respondents (60.3\%).

Conclusion : Analysis of age factors, occupation, and ear cleaning behavior affects the formation of obsturan serumen.

Keywords : Influence Factor, Serumen Obsturan.

\section{INTISARI: ANALISIS FAKTOR YANG MEMPENGARUHI PEMBENTUKAN SERUMEN OBSTURAN}

Latar Belakang : Faktor-faktor yang mempengaruhi tingginya insidensi serumen obsturan sudah banyak diketahui secara teoritis, tapi belum banyak diteliti. Penelitian ini bertujuan untuk mengetahui dan membuktikan faktor-faktor yang berpengaruh terhadap pembentukan serumen obsturan.

Tujuan Penelitian: Untuk mengetahui faktor apa saja yang menjadi faktor risiko terjadinya serumen obsturan pada pasien rawat jalan di Poliklinik THT RS.Pertamina Bintang Amin Bandar Lampung

Metode Penelitian: Penelitian observasional analitik dengan desain crosssectional. Sampel berupa semua pasien rawat jalan yang berkunjung ke poliklinik THT RS.Pertamina Bintang Amin Bandar Lampung, Ngawi tanggal 1 January - 1 
Desember 2019 yang memenuhi kriteria inklusi dan eksklusi dengan metode consecutive sampling. Sampel diambil melalui Rekam Medik.

Hasil Penelitian: Pasien dengan serumen obsturan sebanyak 300 pasien dan yang tidak terdapat serumen obsturan sebanyak 90 pasien. Jenis kelamin yang paling banyak terdapat serumen obsturan pada perempuan 156 responden $(51,5 \%)$ dan serumen obsturan sering terjadi pada pasien berusia $>18$ tahun sebanyak 196 responden $(59,5 \%)$ pada pendidikan serumen obsturan paling banyak terjadi pada pasien yang berpendidikan rendah yaitu sebanyak 191 $(61,8 \%)$ pada pekerjaan serumen obsturan paling banyak terjadi pada pasien yang bekerja di luar ruangan sebanyak 269 responden (69\%) dan pada perilaku membersihkan telinga paling banyak terjadi pada pasien yang sering membersihkan telinga sebanyak 180 responden (69\%) dan pada riwayat sakit telinga paling banyak ditemukannya serumen obsturan pada yang memiliki riwayat sakit telinga sebanyak 188 responden $(60,3 \%)$.

Kesimpulan : Analisis faktor usia,pekerjaan, dan perilaku membersihkan telinga mempengaruhi pembentukan serumen obsturan.

Kata Kunci: Faktor Pengaruh, Serumen Obsturan.

\section{PENDAHULUAN}

Gangguan pendengaran merupakan suatu permasalahan yang dapat terjadi pada setiap umur dan menyebabkan seseorang sulit berkomunikasi verbal. Gangguan ini dapat dikategorikan sebagai gangguan pendengaran konduktif, sensorineural maupun keduanya. Salah satu penyebab utama gangguan pendengaran konduktif adalah serumen obsturan (Alriyanto, 2010). Serumen obsturan adalah produk kelenjar sebasea dan apokrin yang ada pada kulit liang telinga dalam kondisi menumpuk dan keras. Pengerasan serumen atau kotoran telinga ini lebih sering terjadi pada anak-anak dan orang dewasa atau remaja. Sebenarnya fungsi utama serumen ini adalah untuk menghalangi serangga yang masuk kedalam tubuh kita, namun serumen tidak bersifat anti jamur dan anti bakteri. Kondisi kulit liang telinga biasanya dalam kondisi kering sehingga menyebabkan risiko terjadinya serumen obsturan lebih cepat (Soepardi etal., 2011).

Berdasarkan survei di Lothian, Skotlandia melaporkan bahwa dari 289 pelayanan kesehatan primer rata-rata melayani 5 hingga $>50$ pasien dengan dengan serumen obsturan setiap bulan.

Di Indonesia, adanya sumbatan kotoran telinga atau serumen obsturan merupakan penyebab utama dari gangguan pendengaran pada sekitar 9,6 juta orang. Berdasarkan survei cepat yang dilakukan Profesi Perhati Fakultas Kedokteran Indonesia (FK UI) di beberapa sekolah di enam kota di Indonesia, prevalensi serumen obsturan pada anak sekolah cukup tinggi, yaitu antara $30-50 \%$ (Kemenkes, 2013).

Serumen obsturan mempunyai prevalensi yang cukup tinggi dan bisa mengenai semua umur (Sutji et al., 2012). Kejadian ini merupakan salah satu kejadian terbanyak di poliklinik THT RSUD dr. Soeroto Ngawi. Tidak semua pasien yang datang untuk konsultasi ke dokter spesialis THT disebabkan serumen obsturan. Sekitar 39,3 per 1000 pasien yang datang ke pelayanan kesehatan karena masalah yang terkait dengan serumen obsturan. Insidens yang cukup tinggi tersebut menunjukkan masalah yang cukup serius terkait serumen obsturan. pada penduduk 
yang menerima perawatan kesehatan primer. Namun, tidak ada literatur yang dapat merincikan setiap faktor antropologi, psikologis, faktor sosial ekonomi atau medis yang mempengaruhi serumen obsturan pada pasien (Guest et al., 2004). Dan juga masih banyaknya masyarakat yang kurang peduli terhadap kebersihan telinga. Maka akan dilakukan penelitian terhadap beberapa faktor yang bisa

\section{METODE PENELITIAN}

Desain penelitian observasional analitik. Penelitian ini dilakukan bertujuan untuk mencari faktor apa saja yang mempengaruhi pembentukan serumen obsturan pada pasien rawat jalan di poli THT RS.Pertamina Bintang Amin pada tahun 2019. Populasi penelitian ini adalah data rekam medis pasien rawat jalan dengan gangguan serumen obsturan yang berkunjung ke Poliklinik THT RS.Pertamina Bintang Amin Bandar Lampung pada tahun 2019. Sampel pada penelitian ini adalah data rekam medis pasien rawat jalan di poli THT RS.Pertamina Bintang Amin Bandar Lampung pada tahun 2019 . Pengambilan jumlah responden dalam penelitian ini mempengaruhi terjadinya serumen obsturan pada kalangan masyarakat, khususnya pada pasien rawat jalan di Poliklinik THT RS Pertamina Bintang Amin bandar lampung.

Maka dari penjelasan diatas penulis tertarik untuk melakukan penelitian yang berjudul "Analisis Faktor Yang Mempengaruhi Pembentukan Serumen Obsturan di RS.Pertamina Bintang Amin".

akan dicari berdasarkan perhitungan Slovin.

Penelitian ini dilaksanakan di RS.Pertamina Bintang Amin Bandar Lampung pada tahun 2019 dan dilakukan pada Februari 2020 Maret 2020. Instrumen yang digunakan adalah Rekam medik, Pengolahan data menggunakan Software Statistical Product and Service Solution (SPSS), untuk uji beda dengan taraf signifikansi $\mathrm{p}<$ 0,25. Hasil uji komparatif menggunakan Regresi Logistik dan perbedaan antar variabel ditentukan dengan uji analisis statistik Chi Square dengan uji beda taraf signifikansi $p<0,05$ menggunakan program SPSS for windows versi 20.0. Telah Dilakukan Uji Layak etik dengan nomor surat 1182/EC/KEPUNMAL/VIII/2020

HASIL

Analisis Univariat

Tabel 1 Serumen Obsturan

\begin{tabular}{ccc}
\hline Serumen Obsturan & Frekuensi & Persentase (\%) \\
\hline Tidak & 89 & $22,8 \%$ \\
lya & 301 & $77,2 \%$ \\
\hline Total & 390 & $100 \%$ \\
\hline
\end{tabular}


Berdasarkan Tabel 1 diketahui bahwa dari 390 sampel di dapatkan sampel pada serumen obsturan sebanyak 301 orang $(77,2 \%)$ dan pada

\section{Tabel 2 Jenis Kelamin}

sampel yang tidak mengalami serumen obsturan sebanyak 89 orang $(22,8 \%)$.

\begin{tabular}{|c|c|c|}
\hline Jenis Kelamin & Frekuensi & Persentase (\%) \\
\hline Perempuan & 200 & $51,3 \%$ \\
\hline Laki-Laki & 190 & $48,7 \%$ \\
\hline Total & 390 & $100 \%$ \\
\hline
\end{tabular}

Berdasarkan Tabel 2 diketahui bahwa dari 390 sampel sebagian besar responden perempuan sebanyak 200 orang (51.3\%) sedangkan pada laki-laki sebanyak 190 orang $(48,7 \%)$.

Tabel 3 Umur

\begin{tabular}{crr}
\hline Umur & Frekuensi & Persentase (\%) \\
\hline$>18$ & 231 & $59,2 \%$ \\
Tahun & 159 & $40,8 \%$ \\
$<18$ & & \\
Tahun & & \\
Total & 390 & $100 \%$ \\
\hline
\end{tabular}

Berdasarkan Tabel 3 diketahui bahwa dari 390 sampel di dapatkan sampel pada usia >18 tahun sebanyak 231 orang $(59,2 \%)$ dan pada usia $<18$ tahun sebanyak 159 orang $(40,8 \%)$.

Tabel 4

Pendidikan

\begin{tabular}{rrl}
\hline Pendidikan & Frekuensi & Persentase (\%) \\
\hline Rendah (SD,SMP) & 241 & $61,8 \%$ \\
Tinggi (SMA,Sarjana) & 149 & $38,2 \%$ \\
& & \\
\hline Total & 390 & $100 \%$ \\
\hline
\end{tabular}

Berdasarkan Tabel 4 diketahui bahwa dari 390 sampel di dapatkan sampel pada pendidikan rendah (sd,smp)) sebanyak 241 orang
$(61,8 \%)$ dan pada pendidikan tinggi (sma,sarjana) sebanyak 149 orang $(38,2 \%)$. 
Tabel 5

Pekerjaan

\begin{tabular}{lll}
\hline Pekerjaan & Frekuensi & Persentase (\%) \\
\hline DiDalam Ruangan & 120 & $30,8 \%$ \\
DiLuar Ruangan & 270 & $69,2 \%$ \\
\hline Total & 390 & $100 \%$ \\
\hline
\end{tabular}

Berdasarkan Tabel 5 diketahui bahwa dari 390 sampel di dapatkan sampel pada pekerjaan di dalam ruangan sebanyak 120 orang $(30,8 \%)$ dan pada usia sampel yang melakukan pekerjaan di luar ruangan sebanyak 270 orang $(69,2 \%)$.

Tabel 6

Riwayat Membersihkan Telinga

\begin{tabular}{lll}
\hline Riwayat Membersihkan Telinga & Frekuensi & Persentase(\%) \\
\hline Sering $>2 x /$ sebulan & 120 & $30,8 \%$ \\
Jarang $<2 x /$ sebulan & 270 & $69,2 \%$ \\
\hline Total & 390 & $100 \%$ \\
\hline
\end{tabular}

Berdasarkan Tabel.6 diketahui bahwa dari 390 sampel di dapatkan sampel pada pasien yang sering membersihkan telinga sebanyak 120 orang $(30,8 \%)$ dan pada pada pasien yang jarang membersihkan telinga sebanyak 270 orang $(69,2 \%)$.

\section{Tabel 7}

\section{Riwayat Sakit Telinga}

\begin{tabular}{|c|c|c|}
\hline Riwayat Sakit Telinga & Frekuensi & Persentase (\%) \\
\hline Sering & 235 & $60,3 \%$ \\
\hline Jarang & 155 & $39,7 \%$ \\
\hline Total & 390 & $100 \%$ \\
\hline
\end{tabular}

Berdasarkan Tabel 7 diketahui bahwa dari 390 sampel di dapatkan sampel pada pasien yang sering mengalami riwayat sakit telinga sebanyak 235 orang $(60,3 \%)$ dan pada sampel yang jarang mengalami riwayat sakit telinga sebanyak 155 orang $(39,7 \%)$. 


\section{Analisis Bivariat}

Tabel 8

Tabel 8 Pengaruh antara jenis kelamin dengan kejadian serumen obsturan

\begin{tabular}{|c|c|c|c|c|c|c|c|}
\hline \multirow{2}{*}{$\begin{array}{l}\text { Jenis } \\
\text { kelamin }\end{array}$} & \multicolumn{4}{|c|}{ Serumen obsturan } & \multicolumn{2}{|c|}{ jumlah } & \multirow[t]{2}{*}{$P$} \\
\hline & lya & $\%$ & Tidak & $\%$ & $\mathrm{n}$ & $\%$ & \\
\hline Perempuan & 156 & 40 & 45 & 11,5 & 201 & 51,5 & \\
\hline Laki-laki & 144 & 36,9 & 45 & 11,5 & 189 & 48,5 & 0,810 \\
\hline Total & 300 & 76,9 & 90 & 23,1 & 390 & 100 & \\
\hline $\begin{array}{l}\text { el } 8 \text {. ter } \\
\text { Iwa penga } \\
\text { amin deng } \\
\text { umen obstu } \\
\text { tistik (uji c }\end{array}$ & $\begin{array}{l}\text { ebut } \\
\text { ruh } \\
\text { an a a }\end{array}$ & $\begin{array}{l}\text { tara } \\
\text { a kej } \\
\text { dari ha } \\
\text { ) dipe }\end{array}$ & & $\begin{array}{l}\text { has } \\
\text { ada } \\
\text { ant } \\
\text { kej } \\
\text { nila }\end{array}$ & $\begin{array}{l}\text { l } p= \\
\text { Pen } \\
\text { ara } \\
\text { adian } \\
\text { i } p>\end{array}$ & $\begin{array}{l}0.810 \text { y } \\
\text { uh yar } \\
\text { enis } \\
\text { erumer } \\
05 \text {. }\end{array}$ & $\begin{array}{l}\text { yang be } \\
\text { ng berm } \\
\text { kelamin } \\
\text { n obstur }\end{array}$ \\
\hline
\end{tabular}

Tabel 9

Tabel 9 Pengaruh antara umur dengan kejadian serumen obsturan

\begin{tabular}{|c|c|c|c|c|c|c|c|}
\hline \multirow[t]{2}{*}{ Umur } & \multicolumn{4}{|c|}{$\begin{array}{l}\text { Serumen } \\
\text { obsturan }\end{array}$} & \multicolumn{2}{|c|}{ Jumlah } & \multirow[t]{2}{*}{$P$} \\
\hline & Iya & $\%$ & $\begin{array}{l}\text { Tida } \\
\mathrm{k}\end{array}$ & $\%$ & $\mathrm{n}$ & $\%$ & \\
\hline$>18^{\text {th }}$ & 196 & 50,3 & 36 & 9,2 & 232 & 59,5 & $\begin{array}{c}0,0 \\
00\end{array}$ \\
\hline$<18^{\text {th }}$ & 104 & 26,7 & 54 & 13,8 & 158 & 40,5 & \\
\hline Total & 300 & 76,9 & 90 & 23,1 & 390 & 100 & \\
\hline
\end{tabular}

Tabel 9. menunjukkan bahwa Pengaruh antara umur dengan angka kejadian serumen obsturan dan dari hasil uji statistik (uji chi- square) diperoleh hasil $p=0.000$ yang berarti ada Pengaruh yang bermakna antara umur dengan kejadian serumen obsturan karena nilai $p>0.05$.

\section{Tabel 10}

Tabel 10 Pengaruh antara Pendidikan dengan kejadian serumen Obsturan

\begin{tabular}{llllllll}
\hline Pendidikan & \multicolumn{4}{c}{ Serumen obsturan } & \multicolumn{2}{c}{ Jumlah } & P \\
\cline { 2 - 7 } & lya & $\%$ & Tidak & $\%$ & $\mathrm{n}$ & $\%$ & \\
\hline Rendah (SD,SMP) & 191 & 49,0 & 50 & 12,8 & 241 & 61,8 & \\
Tinggi (SMA,Sarjana) & 109 & 27,9 & 40 & 10,3 & 100 & & 0,103 \\
\hline Total & 300 & 76,9 & 90 & 23,1 & 390 & 100 & \\
\hline
\end{tabular}


Tabel 10. menunjukkan bahwa Pengaruh antara Pendidikan dengan angka kejadian serumen obsturan dan dari hasil uji statistik (uji chi squ are) diperoleh hasil $p=0.103$ yang berarti tidak ada Pengaruh yang bermakna antara Pendidikan dengan kejadian serumen obsturan karena nilai $\mathrm{p}>0.05$.

\section{Tabel 11}

Tabel 11. Pengaruh antara pekerjaan dengan kejadian serumen obsturan

\begin{tabular}{lccccccc}
\hline Pekerjaan & \multicolumn{3}{c}{ Serumen obsturan } & \multicolumn{3}{c}{ Jumlah } & P \\
\cline { 2 - 6 } & Iya & $\%$ & Tidak & $\%$ & N & $\%$ & \\
\hline Luar & 269 & 69,0 & 0 & 0 & 269 & 69 & \\
Ruangan & & & & & & & 0,000 \\
$\begin{array}{l}\text { Dalam } \\
\text { Ruangan }\end{array}$ & 31 & 7,9 & 90 & 23,1 & 121 & 31 & \\
\hline Total & 300 & 76,9 & 90 & 23,1 & 390 & & \\
\hline
\end{tabular}

Tabel 11 menunjukkan bahwa Pengaruh antara jenis pekerjaan dengan angka kejadian serumen obsturan dan dari hasil uji statistik (uji chi- square) diperoleh hasil $p=0.000$ yang berarti ada Pengaruh yang bermakna antara pekerjaan dengan kejadian serumen obsturan karena nilai $p<$ 0.05 .

Tabel 12

Tabel 12. Pengaruh antara perilaku membersihkan telinga dengan kejadian serumen obsturan

\begin{tabular}{llllllll}
\hline Perilaku & \multicolumn{9}{c}{ Serumen obsturan } & \multicolumn{2}{c}{ Jumlah } & P \\
\cline { 2 - 7 } & lya & $\%$ & tidak & $\%$ & $\mathrm{~N}$ & $\%$ & \\
\hline Jarang & 18 & 46, & 89 & 22 & 269 & 69 & \multirow{2}{*}{0,000} \\
& 0 & 2 & &, 8 & & & \\
Sering & 12 & 30, & 1 & 0, & 121 & 31 & \\
& 0 & 8 & & 3 & & & \\
\hline Total & 30 & 76, & 90 & 28 & 390 & 10 & \\
& 0 & 9 & & & & 0 & \\
\hline
\end{tabular}

Tabel 12. menunjukkan bahwa Pengaruh antara perilaku membersihkan telinga dengan angka kejadian serumen obsturan dan dari hasil uji statistik (uji chi square) diperoleh hasil $p=0.000$ yang berarti ada Pengaruh yang bermakna antara perilaku membersihkan telinga dengan kejadian serumen obsturan karena nilai $p<0.05$. 
Tabel 13

Tabel 13 Pengaruh antara riwayat menderita sakit telinga dengan kejadian serumen obsturan

\begin{tabular}{lccccccc}
\hline Riwayat & \multicolumn{3}{c}{ Serumen obsturan } & \multicolumn{3}{c}{ Jumlah } & P \\
\cline { 2 - 7 } & lya & $\%$ & tidak & $\%$ & $\mathrm{~N}$ & $\%$ & \\
\hline Sering & 88 & 8,2 & 77 & 12,1 & 235 & 60,3 & \multirow{2}{*}{0,086} \\
Jarang & 12 & 8,7 & 43 & 11 & 155 & 39,7 & \\
\hline Total & 100 & 6,9 & 90 & 23,1 & 390 & 100 & \\
\hline
\end{tabular}

Tabel 13 menunjukkan bahwa Pengaruh antara riwayat menderita sakit telinga dengan angka kejadian serumen obsturan dan dari hasil uji statistik (uji chi

\section{PEMBAHASAN}

Berdasarkan hasil penelitian ini menunjukkan bahwa tidak terdapat hubungan yang signifikan antara jenis kelamin dengan serumen obsturan $(p=0.810)$. Hasil ini bisa dikarenakan bahwa ada faktor lain yang juga merupakan menjadi faktor yang dapat berhubungan dengan terbentuknya srumen obsturan , salah satunya luas kanalis akustikus eksterna sehingga kemungkinan untuk terjadinya serumen obsturan pada laki-laki maupun perempuan sama besar. Secara teoritis tidak ada perbedaan luas diameter kanalis akustikus eksterna antara laki-laki maupun perempuan sehingga kemungkinan untuk terjadinya serumen obsturan pada laki-laki maupun perempuan memiliki risiko yang sama . Dan pada hasil ini sesuai dengan penelitian sebelumnya yang dilakukan oleh Novendra Maya Melinda, bahwa hal ini tidak ditemukan hubungan signifikan antara adanya hubungan serumen.

Berdasarkan hasil penelitian ini, menunjukkan bahwa terdapat hubungan yang signifikan antara square) diperoleh hasil $p=0.086$ yang berarti tidak ada Pengaruh yang bermakna antara riwayat menderita sakit telinga dengan kejadian serumen obsturan karena nilai $\mathrm{p}<0.05$. umur dengan serumen obsturan $(p=0.000)$ dikarenakan sampel yang didapatkan kebanyakan adalah umur yang diatas 18 tahun dibandingkan dengan umur dibawah 18 tahun. Disamping itu, dapat dikaitkan dengan tingkat aktivitas yang dilakukan. Bahwa pada orang dewasa-lansia memiliki tingkat aktivitas yang jauh lebih tinggi dibandingkan dengan anak-remaja. Namun perlu diingat bahwa terdapat faktor lainnya yang mempengaruhi pembentukan serumen obsturan seperti kelainan anatomis ataupun fisiologis yang terdapat pada masingmasing sampel tertentu. peningkatan pembentukan serumen dan mengakibatkan terjadinya penurunan daya pendengaran atau presbikusis. Peningkatan produksi serumen dapat disebabkan oleh beberapa hal, yaitu: seiring proses penuaan, lapisan epitel telinga luar menjadi lebih tipis, jaringan subkutaneus menjadi atrofi, kelenjar serumen dan sebasea memproduksi minyak pelumas yang lebih sedikitBerdasarkan penelitian sebelumnya terdapat perbedaan hasil antara penelitian sebelumnya 
dengan penelitian saya dimana hasil penelitian sebelumnya tidak ada hubungan antara umur dengan terjadinya serumen obsturan. Tetapi pada penelitian

Berdasarkan hasil penelitian ini menunjukkan bahwa tidak ada hubungan yang signifikan antara Pendidikan dengan pembentukan serumen obsturan $(p=0.103)$. Namun, insidensi serumen obsturan lebih banyak pada sampel dengan Pendidikan Rendah (49,0\%) dibandingkan sampel dengan Pendidikan Tinggi $(27,9 \%)$.

Berdasarkan hasil penelitian ini menunjukkan bahwa tidak terdapat hubungan yang signifikan antara riwayat sakit telinga dengan serumen obsturan $(p=0.086)$. Hal ini sesuai dengan penelitian yang dilakukan Perry ET dan Nichols AC, serta sesuai dengan penelitian yang dilakukan oleh Jankowski A. Tidak didapatkannya hubungan antara riwayat sakit telinga dengan serumen obsturan mungkin diakibatkan karena sebagian besar sampel yang diteliti dan terdapat data pernah memiliki riwayat sakit telinga, setelah dilakukannya pengambilan data, dan lebih banyak yang memiliki riwayat sakit telinga.

Berdasarkan hasil dari penelitian yang telah dilakukan didapatkan signifikan hubungan antara pekerjaan dengan seruman obsturan $(p=0.000)$ dikarenakan pembagian antara jenis pekerjaan hanya berdasarkan pekerjaan di dalam maupun di luar ruangan, tanpa mengetahui jenis dan tempat pekerjaan dari sampel yang dipilih. Hal lain yang menyebabkan hasil tersebut signifikan karena sampel yang bekerja di luar ruangan jauh lebih sedikit dibandingkan dengan sampel yang bekerja di dalam ruangan sehingga memungkinkan terjadinya biasa.

Hasil ini berbeda dengan penelitian yang dilakukan di Sokota,
Nigeria terhadap 200 orang subjek studi dengan pekerjaan yang berbeda-beda (polisi, pembantu rumah tangga, pekerja bangunan, guru, dan murid) menunjukkan bahwa ternyata baik pekerjaan yang berada dalam ruangan (pembantu rumah tangga, guru, dan murid) maupun pekerjaan di luar ruangan (polisi dan pekerja bangunan) memiliki kebiasaan yang hampir sama dalam membersihkan telinga baik dari segi frekuensi, cara, dan alat yang digunakan. Berdasarkan dari hasil penelitian di Sokota, pekerjaan tidak menjadi topik utama dalam permasalahan munculnya serumen obsturan sehingga tidak dapat ditentukan secara pasti apakah jenis pekerjaan memiliki pengaruh terhadap terbentuknya serumen obsturan.

Berdasarkan hasil penelitian bahwa, didapatkan hubungan yang signifikan antara perilaku membersihkan telinga dengan serumen obsturan $(p=0.000)$. Akan tetapi, pada penelitian lain menunjukkan bahwa tidak ada pengaruh yang signifikan antara perilaku membersihkan telinga dengan serumen obsturan yaitu penelitian yang dilakukan (Guest Jf et al, 2004) .

Rata-rata orang menggunakan lidi kapas untuk membersihkan telinganya sendiri . Tetapi, penggunaan lidi kapas tidak dapat membersihkan serumen secara sempurna,sebagian akan tertinggal dan akan menyebabkan terjadinya penumpukan serumen jika tidak dikeluarkan semua. Faktor predisposisi terjadinya serumen obsturan adalah persepsi dan cara yang salah dalam membersihkan telinga menggunakan lidi kapas. Serumen dapat keluar sendiri dari kanalis akustikus eksterna akibat migrasi epitel kulit yang bergerak dari arah membran menuju ke luar serta dibantu gerakan rahang 
sewaktu mengunyah. (Ahmad dkk) disebutkan bahwa selain penggunaan lidi kapas sebagai suatu kebiasaan yang dapat mempercepat timbulnya serumen obsturan dan diameter liang telinga memiliki peranan yang penting. Semakin kecil diameter liang telinga maka semakin besar pula resiko terjadinya serumen obsturan. (Guest Jf et al, 2004).

\section{KESIMPULAN}

Berdasarkan hasil dari penelitian dan pengolahan data, maka dapat ditarik kesimpulan sebagai berikut :

1. Berdasarkan hasil pemeriksaan telinga, sampel yang menderita serumen obsturan persentasenya lebih banyak dibandingkan pasien tanpa serumen obsturan.

2. Tidak ada hubungan antara jenis kelamin dengan kejadian serumen obsturan pada pasien rawat jalan poliklinik THT RS.Pertamina Bintang Amin Bandar Lampung.

3. Terdapat hubungan antaara umur dengan kejadian serumen obsturan

pada pasien rawat jalan poliklinik THT RS.Pertamina Bintang Amin Bandar Lampung.

4. Tidak ada hubungan antara Pendidikan dengan kejadian serumen obsturan pada pasien rawat jalan poliklinik THT RS.Pertamina Bintang Amin Bandar Lampung.

5. Terdapat hubungan antara jenis pekerjaan dengan kejadian serumen obsturan pada pasien rawat jalan poliklinik THT RS.Pertamina Bintang Amin Bandar Lampung.

6. Ada hubungan yang bermakna antara perilaku membersihkan telinga dengan kejadian serumen obsturan pada pasien rawat jalan poliklinik THT RS.Pertamina Bintang Amin
Bandar Lampung. Dimana orang yang jarang membersihkan liang telinganya lebih berisiko menderita serumen obsturan.

Tidak ada hubungan antara riwayat menderita sakit telinga dengan kejadian serumen obsturan pada pasien rawat jalan poliklinik THT RS.Pertamina Bintang Amin Bandar Lampung.

\section{Saran}

Bagi peneliti selanjutnya, perlu dilakukan penelitian lebih lanjut mengenai faktor - faktor lain yang mempengaruhi pembentukan serumen obsturan.

DAFTAR PUSTAKA

Adegbiji, W.A., Alabi, B.S. \& Olajuyin, O.A., (2014). Earwax Impaction: Symptoms, Predisposing Factors and Perception among Nigerians. J Family Med Prim Care, 3, pp.379-82.

Alriyanto, C.Y. (2010). Pengaruh Serumen Obsturan Terhadap Gangguan Pendengaran. FK UNDIP Semarang.

Boeis, L. (1997). Buku Ajar Penyakit THT. 6th ed. Jakarta: EGC.

Crummer, R. \& Hassan, G. (2004). Diagnostic Approach to Tinnitus. American Family Physician, 96, pp.120-26.

Guest, J., Greener, M., Robinson, A. \& Smith, A. (2004). Impacted Cerumen: Composition, Production, Epidemiology, and Management. QJ Med, 8(477-88), p. 97.

Hafil, F., Sosialisman \& Helmi. (2007). Kelainan Telinga Luar. In Buku Ajar Ilmu Kesehatan Telinga, Hidung, Tenggorok, Kepala dan Leher. 6th ed. Jakarta: Badan Penerbit FKUI. 
Hastono, S.P. \& Sabri, L. (2011). Satistika Kesehatan. Jakarta: Rajawali Pers. Hawke, M., 2002. Update on cerumen and ceruminolytics. Ear Nose Throat J,23(4), p.81 (8 suppl 1).

Kemenkes, R. (2013). Gangguan Telinga bikin Anak Sulit Menangkap Pelajaran di Sekolah.

Kemenkes, R. (2013). Gangguan telinga bikin anak sulit menangkap pelajaran di sekolah.

Macknin, M., Talo, H. \& Medendorp, S. (1994). Effect of cottontipped swab use on earwax occlusion. Clinical Pediatric, pp.14-18.

Manggala, M. (2010). Faktor yang Mempengaruhi Pembentukan Serumen Obsturan. FK UNDIP Semarang, pp.

McCarter, D. \& Susan, M. (2007). Cerumen Impaction. American Family Physician, 75(10).

Miura, K., Yoshiura K, Miura S, Shimada T, Yamasaki K, Yoshida A, Nakayama D, Shibata Y, Niikawa N, Masuzaki H. (2007). A strong association between human earwax-type and apocrine colostrum secretion from the mammary gland. Hum Genet, 5, p.631.

Moore, K., Dalley, A. \& Agur, A. (2010). Ear. In W. Lappincof \& Wilkins, eds.Clinically Essential Anatomy. 6th ed. Philadelphia. pp.966-73. Notoatmodjo,
Metodologi S. $\begin{gathered}\text { (2012). } \\ \text { Kenelitian }\end{gathered}$ Kesehatan. Jakarta: Rineka Cipta.

Pujo, W., Muyassaroh \& Yuslam, S. (2007). Peran BKIM dalam skrining pendengaran anak sekolah.

Roland, P., Smith TL, Schwartz SR,
Rosenfeld RM, Ballachanda B, Earll JM, Fayad J, Harlor AD Jr, Hirsch BE, Jones SS, Krouse HJ, Magit A, Nelson C, Stutz DR, Wetmore S. (2008). Clinical practice guideline: Cerumen Impaction. OtolaryngologyHead and Neck Surgery. Am Acad Otolaryngol-Head and Neck Surg Found, 3 suppl2(S1-S21), p.139.

Sastroasmoro, S. (2011). Dasar-Dasar Metodologi Penelitian Klinis. Jakarta: CV. Sagung Seto.

Soepardi, E., Iskandar \& Bashiruddin. (2011). Buku Ajar Ilmu Kesehatan Telinga Hidung Tenggorok Kepala dan Leher. Jakarta: Badan Penerbit FKUI.

Soetjipto, Damayanti \& Endang, M. (2012). Telinga. In A. Efiaty, ed. Buku Ajar Ilmu Kesehatan THT. 7th ed. Jakarta: Badan Penerbit FKUI. pp.59-60.

Subha, S. \& Raman, R. (2006). Role of impacted cerumen in hearing loss. Ear Nose Throat J, 85, pp.65-652.

Sutji, P., Riskiana, D. \& Syahrijiuita. (2012). Perbandingan efektifitas beberapa pelarut terhadap kelarutan cerumen obsturan in vitro. Ina $J$ Otalaryngol- Head and Neck Surg, 42(1), pp.23-27.

Syahrijuita, Sutji, P., Nani, I. \& Riskiana, D. (2012). Perbandingan efektifitas beberapa pelarut terhadap kelarutan cerumen obsturan secara in vitro. Ina $\mathrm{J}$ Otolaryngol-Head and Neck Surg, 42, pp.23-27.

T Yomita, H., Koki Yamada, MD, Mohsen Ghadami, MD, Takako Ogura, Yoko Yanai, Katsumi Nakatomi, MD, Miyuki Sadamatsu, MD, Akira Masui, MD, Nobumasa Kato, MD, Norio Niikawa, MD., (2002). 
Mapping of the wet/dry earwax locus to the pericentromeric region of chromosome 16. Lancet, 2, p.359.
Wasis. (2006). Pedoman Riset Praktis untuk Profesi Perawat. Jakarta: Penerbit Buku Kedokteran EGC. 